\title{
Densification, Grain Growth and Microstructure of Ni-Zn Ferrites
}

\author{
B. Parvatheeswara Rao, P.S.V. Subba Rao and K.H. Rao \\ Department of Physics, Andhra University, Visakhapatnam 530003, India
}

\begin{abstract}
Ni}_{0.65} \mathrm{Zn}_{0.35} \mathrm{Fe}_{2} \mathrm{O}_{4}$, with high density and fine grain size, is a desirable composition for applications of high frequency switching power supplies. This composition has been studied under different sintering conditions. Observed changes in density, grain size and microstructure in these ferrites have been correlated to the volatilization of zinc from the samples at elevated sintering temperatures. Densification and grain growth are observed to be Arrhenius controlled rate processes with activation energies of 63.9 and $64.4 \mathrm{Kcal} / \mathrm{mole}$ respectively.
\end{abstract}

\section{INTRODUCTION}

Ferrite properties depend very strongly on the chemical composition and the microstructure. Since the development of a microstructure is sensitive to sintering, a study of ferrites under different sintering schedules is necessary to optimize the given composition for any specific application. Densification and grain growth take place simultaneously during sintering leading to an increase in grain size $\left(D_{m}\right)$ and change in pore structure which affect ferrite properties significantly. Since the microstructures developed at various stages of sintering are influenced by sintering kinetics [1], the study of sintering kinetics is thus useful in understanding various properties of the ferrites. The present study deals with densification and grain growth rates occurring in $\mathrm{Ni}_{0.65} \mathrm{Zn}_{0.35} \mathrm{Fe}_{2} \mathrm{O}_{4}$ system and includes a discussion on the resulting changes in the microstructure.

\section{EXPERIMENTAL DETAMS}

Samples of the composition $\mathrm{Ni}_{0.65} \mathrm{Zn}_{0.35} \mathrm{Fe}_{2} \mathrm{O}_{4}$ have been prepared at different sintering temperatures in the range from 1150 $-1300^{\circ} \mathrm{C}$ for varied sintering times from 1 to 4 hours at each temperature by conventional ceramic method. X-ray diffraction studies confirm single phase spinel structure in all the cases. Bulk densities were determined by Archimedes principle and microstructural studies were carried out by using JEOL T 330A Scanning Electron Microscope.

\section{RESULTS AND DISCUSSION}

Observed microstructures of $\mathrm{Ni}_{0.65} \mathrm{Zn}_{0.35} \mathrm{Fe}_{2} \mathrm{O}_{4}$ studied at various sintering conditions show a very uniform matrix of small grains with entire porosity being intergranular (Fig. 1). However, the density and grain sizes of these ferrites have been found to increase with the increase of sintering time as well as sintering temperature. The relations between percent densification versus sintering time and $\mathrm{D}_{\mathrm{m}}^{2}$ versus sintering time for various sintering temperatures are shown in figures $2 \mathrm{a}$ and $2 \mathrm{~b}$.
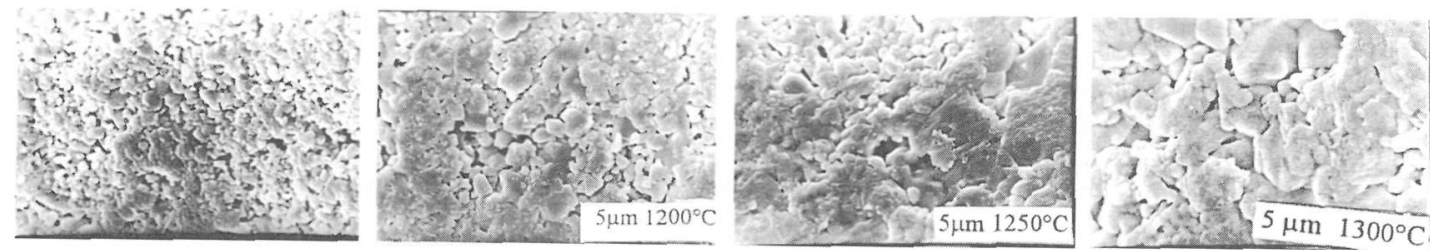

Fig. 1. Typical microstructures of $\mathrm{Ni}_{0.65} \mathrm{Zn}_{0.35} \mathrm{Fe}_{2} \mathrm{O}_{4}$ for various sintering temperatures sintered at 4 hours. 
Activation energy ( $Q$ ) for the densification process has been estimated from the Arrhenius equation

$$
1 / t=k_{0} \exp (-Q / R T)
$$

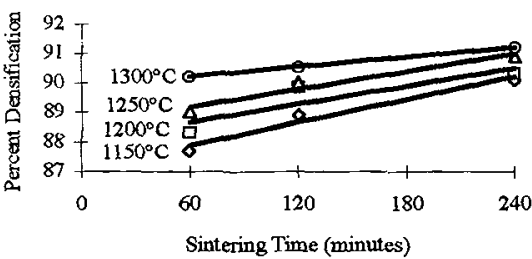

Fig 2a. Percent densification versus sintering time.

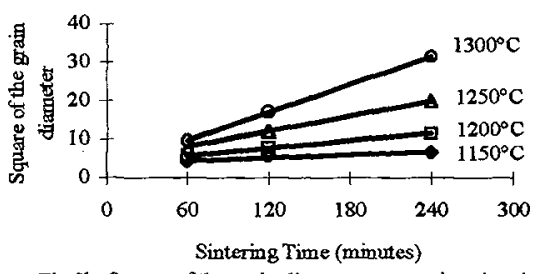

Fig 2b. Square of the grain diameter versus sintering time.

where $k_{0}$ is a proportionality constant, $t$ is the time necessary to attain a density common to the four isotherms and $T$ is the temperature in ${ }^{\circ} \mathrm{K}$. A plot of $\log (1 / \mathrm{t})$ versus $1 / \mathrm{T}$ (Fig. $3 \mathrm{a}$ ) shows a straight line relationship, implying the densification as an Arrhenius-controlled rate process with an activation energy of $63.9 \mathrm{Kcal} / \mathrm{mole}$.

Similarly, since the curves of figure $2 b$ are found to be linear, the relationship can be expressed by the simple relation

$$
\mathrm{D}^{2}=\mathrm{kt}
$$

where $\mathrm{k}$ is a temperature dependent rate constant which can be obtained from the slopes of Fig. $2 \mathrm{~b}$. If there is an increase in temperature, it brings about a corresponding increase in rate $k$ and a plot of $\log k$ versus $1 / T$ (Fig. 3b) shows a straight line relationship implying the grain growth as Arrhenius-controlled process with activation energy of $64.4 \mathrm{Kcal} / \mathrm{mole}$.

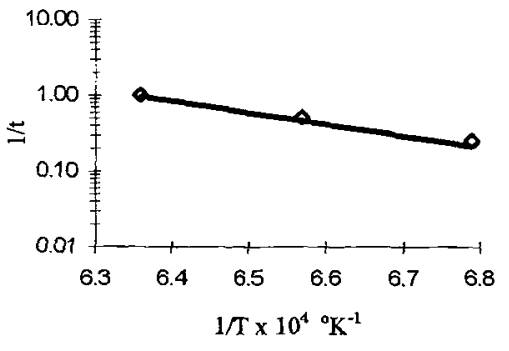

Fig. 3a. Plot of $\log (1 / t)$ versus $1 / T$.

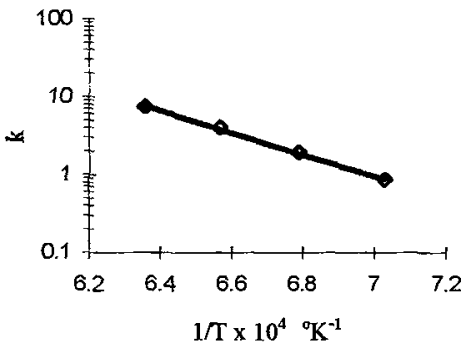

Fig. 3b. Plot of $\log k$ versus $1 / T$.

The observed values of activation energy for densification and grain growth in the present study are relatively low compared with the values reported by Paulus, $83 \mathrm{Kcal} / \mathrm{mole}$ for $\mathrm{Mn}-\mathrm{Zn}$ and $\mathrm{Ni}-\mathrm{Zn}$ ferrites [2] and by Levesque, $90 \mathrm{Kcal} / \mathrm{mole}$ for $\mathrm{Ni}$ ferrites [3]. The deviations and also the related microstructures of these ferrites are explained as follows: Due to volatilization of zinc at higher sintering temperatures, the $\mathrm{Ni}_{0.65} \mathrm{Zn}_{0.35} \mathrm{Fe}_{2} \mathrm{O}_{4}$ composition becomes slightly nonstoichiometric and the excess $\mathrm{Fe}_{2} \mathrm{O}_{3}$, though the X-ray diffraction techniques are not sensitive to detect its presence, dissolves into the spinel lattice partly as $\gamma-\mathrm{Fe}_{2} \mathrm{O}_{3}$ with cation vacancies and partly as $\mathrm{Fe}_{3} \mathrm{O}_{4}$ with formation of $\mathrm{Fe}^{2+}$ ions [4]. The presence of such $\mathrm{Fe}^{2+}$ ions in these materials was confirmed by chemical analysis [5]. As the result of the formation of cation vacancies, the oxygen vacancy concentration will be low and consequently the sintering rate will be relatively slow. Further complication with the excess $\mathrm{Fe}_{2} \mathrm{O}_{3}$ in ferrites is an occurrence of pore growth [4] along with the grain growth which causes a decrease in the density of the final product. The mechanism of grain growth combined with pore growth leads to a microstructure in which the residual porosity is only present in between the grains. The observed microstructures and the values of density and grain size in the present stucty are in agreement with the above arguments.

In conclusion, the increase in sintering temperature rather than sintering time causes more zinc to volatilize from the material thus forcing the composition to become slightly nonstoichiometric. As a result, sintering rate has become relatively slow which in turn prevents the material from attaining higher densities and/or grain sizes.

\section{References}

1. Jain G.C., Das B.K. and Goel N.C., Ind.J.Pure \& Appl.Phys. 14 (1976) 87-92.

2. Paulus M., Proc. Brit. Ceram. Soc. 2 (1962) 1181-1194.

3. Levesque P., Geralch L. and Zneimer J.E., J. Am. Ceram. Soc. 41 (1958) 300

4. Stuijts A.L., Ceramic microstructures (eds: Fulrath R.M. and Pask J.A.) (Westerview Press, 1977) 443.474

5. Parvatheeswara Rao B., Subba Rao P.S.V. and Rao K.H., J. Mater. Sci. Letts. 15 (1996) 781-783. 